REDES- Revista hispana para el análisis de redes sociales

Vol.15,\#6, Diciembre 2008

http: // revista-redes.rediris.es

\title{
La entrevista biográfico-narrativa como expresión contextualizada, situacional y dinámica de la red socio-personal
}

\author{
Carlos Lozares, J oan Miquel Verd - Departament Sociologia (UAB) ${ }^{1}$
}

\section{Resumen}

Este artículo propone un método alternativo al habitual de la encuesta por panel para el estudio de las redes socio-personales. El propósito consiste en analizar la dinámica inherente a las redes socio-personales a través de los relatos obtenidos mediante entrevistas biográfico-narrativas. Este tipo de entrevistas ofrece una información que tratada y analizada mediante los procedimientos habituales en la perspectiva de redes sociales permite revelar los cambios ocurridos en la red de relaciones de la persona entrevistada.

Palabras clave: Redes socio-personales - Entrevista biográfico-narrativa - Tiempo social- Análisis reticular del discurso - Pasajes narrativos

\begin{abstract}
The article proposes an alternative method to the commonly used panel survey in order to analyse social-personal networks. The objective is examining the dynamics inherent to social-personal networks through narratives obtained by means of biographic-narrative interviews. This kind of interviews offers information that when considered and analysed by means of the procedures characteristic of the social networks perspective allow to reveal the changes occurred in the network of relations of the interviewee.
\end{abstract}

Key words: Social-personal networks - Biographic-narrative interview - Social time - Network discourse analysis - Narrative passages.

\section{Introducción}

\section{De qué se trata en este artículo}

Los estudios de redes socio-personales son parte importante del análisis de las Redes Sociales. Más recientemente se ha ido consolidando el análisis de su dinámica, sobre todo por el método de encuesta por panel (Wellman, 1979; Minor, 1983; Suitor et al., 1997; Degenne y Lebeaux, 2005; Bidart y Lavenu, 2005; Bidart y Degenne, 2005).

\footnotetext{
${ }^{1}$ Departamento de Sociología - Centre d’Estudis Sociològics sobre la Vida Quotidiana i el Treball. Enviar correspondencia a: Carlos.Lozares@uab.cat
} 
El propósito del artículo consiste en analizar la dinámica inherente a las redes socio-personales a través de los relatos obtenidos mediante entrevistas biográficonarrativas. Los relatos obtenidos de este modo incorporan un tipo de información pragmática, situacional y contextual que hilvanada temporalmente nos parece muy informativa a la hora de interpretar dichas redes. Dado que las redes sociopersonales cambian a lo largo de una narración biográfica marcando e impregnado el ciclo de vida o el de otras temporalidades, como por ejemplo, la de un día, etc., el relato obtenido constituirá un inmejorable soporte y un objeto de análisis apropiado de la dinámica de las redes socio-personales.

El artículo no realiza un estudio comparado de entrevistas biográfico-narrativas; su objetivo es básicamente metodológico en el sentido de mostrar la eficacia informativa de las entrevistas para el estudio de la dinámica de las redes sociopersonales. Para analizar e interpretar el discurso de la entrevista, proveniente de la dinámica y cambios de las redes socio-personales, será necesario acompañar el examen de la estructura reticular de las situaciones de vida configuradas por la narración, que llamaremos entornos, con el de su sucesión a través de los pasajes reticulares de transición entre dichos entornos. El conjunto revelará la dinámica de los cambios en la narración biográfica y, con ello, su discurso.

\section{La entrevista narrativo-biográfica y las redes socio-personales}

No es habitual el uso de entrevistas narrativo-biográficas como forma de obtener las redes socio-personales de los individuos. Sin embargo el uso de esta técnica ofrece en este campo un conjunto de alicientes que Jovchelovitch y Bauer (2000: 60) y Flick (1998: 101) han resumido acertadamente. Se trata de ventajas que se obtienen globalmente del uso de narraciones biográficas, no necesariamente orientadas al análisis de redes socio-personales, pero que aplicadas a este objetivo concreto mantienen toda su virtualidad. En primer lugar debe destacarse la textura detallada que ofrecen los relatos biográficos. En ellos el narrador tiende a dar tanta información como sea necesario para poder mostrar la transición y vínculos entre unos acontecimientos y otros. La narración debe ser comprensible para el oyente, por lo tanto cuanto menos conozca éste, mayores detalles se darán. Ello supone una gran cercanía a los hechos: se dan detalles sobre el tiempo, los espacios, los motivos, los planes y estrategias, la capacidad y habilidad para afrontar o manejar los acontecimientos... En segundo lugar el relato permite identificar los acontecimientos de mayor importancia de acuerdo con la perspectiva del mundo del narrador. En un relato biográfico aquello que se cuenta es siempre necesariamente selectivo; se desarrolla en torno a núcleos temáticos que son considerados 
relevantes por el narrador, y por lo tanto, cruciales para entender cómo los acontecimientos fueron vividos e influyeron en las acciones tomadas. Estos núcleos temáticos constituyen las estructuras de relevancia de los individuos. En tercer lugar, el relato biográfico permite acceder a acontecimientos, personas, lugares, que, aunque el narrador no exprese manifiestamente su integración directa, sí que adquieren adquieren importancia cuando se presentan conectados con otros hechos mediante la forma narrativa. Esta contextualización e integridad narrativa, permite obtener una globalidad y coherencia informativa difícilmente alcanzable de otro modo.

Las redes socio-personales, pues, en tanto que expresión de relaciones entre actores situadas contextual y temporalmente, quedan fijadas en el relato mediante referencias a espacios sociales, vivencias, transiciones, puntos clave (hitos biográficos) o cambios de rumbo. El relato biográfico se despliega presentando distancias o recorridos diversos (días, semanas, meses, años, toda la vida) con sus correspondientes vínculos entre el narrador y otros actores y de estos actores entre sí, mostrando la malla social que ha rodeado el devenir biográfico del relator. Así, las relaciones (y redes) entre agentes sociales y su evolución, mediando la narración biográfica, aparecen menos preestablecidas, protocoladas e impuestas por el analista, además de 'naturales', situadas y contextualizadas, que las de otros procedimientos de recogida de observación y análisis.

\section{Redes socio-personales, tiempo e historia}

Las redes socio-personales diversas y sucesivas que aparecen en una entrevista narrativa no sólo son el reflejo de la articulación reticular de Nodos que aparecen entorno al Ego entrevistado sino que se insertan en una historia individual que también es social, es decir, generan y se generan en un/os tiempo/s social/es. Estos tiempos socio-individuales, dado que surgen de las sucesivas interacciones biográficas y por tanto de la sucesión de relaciones, son a veces continuos, otras interrumpidos, superpuestos, latentes o reencontrados. De las épocas de la primera socialización a la segunda y de ella a la madurez, etc., aparecen y fenecen nuevos agentes e interacciones que se traducen en la agenda relacional de las personas en nuevos y/o superpuestos entornos. Los periodos de nuestro ciclo personal están marcados por los rasgos de las nuevas relaciones y por las permanentes 0 durmientes del pasado. Este proceso de cambio que se da en las relaciones ocurre también en las representaciones o en las estrategias que tenemos con respecto a ellas. Más, dichos dos procesos, el que opera en la realidad relacional palpable y empírica y el que se da interiorizado en el conocimiento, se re-generan 
mutuamente aunque no sean equivalentes. Quiere decirse que en el análisis longitudinal de las redes socio-personales de una narración pueden emparejarse más fructuosamente el análisis de la facticidad relacional con el de la cognición interiorizada.

No son habituales que los análisis de redes socio-personales, salvo estudios de panel por encuesta como los referenciados la principì, y los sociométricos tengan en cuenta la dimensión temporal. Los agentes y sus relaciones aparecen 'destemporizados' en una especie de fijación sincrónica sin dar al tiempo social todo su potencial de soporte de las relaciones y de capacidad interpretativa. No es que se han de minusvalorar nuestros estudios estáticos, ni mucho menos, pero la toma en consideración de su contexto temporal (dónde y cómo surgen, evolucionan o finiquitan) parece importante para la comprensión de la narración biográfica estudiada.

\section{Redes socio-personales, contextos, estructura y sociedad}

Las relaciones no se producen en el vacío con grados infinitos de libertad sino en entornos sociales preestablecidos, lo que las condiciona o facilita. Sin embargo, a su vez, dichas relaciones generan y refuerzan dichos entornos siendo así parte decisiva para la formación de los mismos. Lo que quiere decir que cualquier análisis de las relaciones o equivalentemente, en el caso, de las redes socio-personales, no ha de ser independiente del entorno y por tanto del contexto en el que se albergan; la viceversa también es necesaria. Si las relaciones o redes socio-personales no se inscriben en un vacío social sino en entornos estructurados y contextuales variarán, a su vez, con los entornos variables en los que se insertan. Se ha de dar pues una correspondencia entre la naturaleza y dinámica de las redes socio-personales y la estructura y cambios de los entornos que las cobijan ya que se generan mutuamente (Erikson, 1982; Gartrell, 1987). El estudio de los entornos cambiantes con sus redes dinámicas inherentes es importante ya que dichos entornos son los nichos de socialización (por ejemplo la familia, escuela, empresa...). Por todo ello, el desarrollo de las redes socio-personales son al mismo tiempo factores y consecuencias de las diferentes socializaciones en los diversos entornos del ciclo de vida.

Este rol de mediación de la red personal reflejo de la vida social del individuo en una situación dentro de un entorno (escolar, familiar, ocio, asociativo, etc.) y la estructura de dicho entorno como parte de una estructura de más envergadura social es lo que confiere además a la red socio-personal una función de revelador 
social: por un lado, son componentes y soportes de la estructura de sus entornos y, por otro, mecanismo de su construcción. De ahí la denominación adoptada de red socio-personal. Así pues, la red socio-personal se inscribe en (y produce) entramado social. Las posiciones relacionales de los Nodos personales en sus entornos contextuales y estructurados son al mismo tiempo recursos y estrategias en vistas a su acción o interacción y también condicionamientos o peajes para la misma acción.

Desde el punto de vista del analista, el conocimiento de las redes socio-personales, de sus entornos y de las evoluciones correspondientes y conjugadas de redes y entornos nos dan pues pistas para el estudio del discurso de las personas como entidades sociales y de las estructuras sociales con las que interaccionan. Dimensión socio-temporal y dimensión socio-estructural se conjurán, diacrónica y sincrónicamente, para un mayor conocimiento social a partir de la red sociopersonal (Bidart y Degenne, 2005; Degenne y Forsé, 2003)

\section{Las preguntas y los supuestos hipotéticos}

Varias cuestiones se plantean a las que, como objetivo del artículo, se trata de aportar alguna respuesta. Cuando se habla de dinámica de las redes sociopersonales ¿de qué tiempo hablamos, del abstracto homogéneo y reductor o del tiempo social múltiple?, ¿es pues múltiple el tiempo social y, si lo es, se darán dinámicas temporales diversas en las redes socio-personales?, ¿de dónde proviene y cómo se genera el tiempo social?, ¿qué tiene que ver el tiempo social, expresión de cambio y de la dinámica social, con las redes socio-personales y su dinámica? El siguiente apartado 1 trata de responder a estas preguntas.

¿Cómo se traduce en el análisis de la entrevista narrativo-biográfica la estática y dinámica del modelo sincrónico y diacrónico, que se presenta en este artículo, en el que se conjuguen por un lado, las redes socio-personales con sus dinámicas y trayectorias expresadas en la narración biográfica y, por otro, los entornos sociales en los que se insertan como contextos estructurales y su cambo en el tiempo?, ¿qué añade la entrevista narrativo-biográfica, como metodología, a los análisis de paneles comparados en el tiempo?. En definitiva, ¿expresa la entrevista las marcas que la historia y la estructura social han dejado en la trayectoria socio-reticular de la persona y, a su vez, se mostrará, por la red socio-personal, como expresión de una trayectoria y/o ciclo vital, la impronta que el individuo ha dejado en la historia y en la estructura social? (Bidart y Degenne, 2005). A esta estas cuestiones se 
responde en los apartados 2 y 3, y también en el 4, más dedicado a la ejemplificación a fin de corroborar la propuesta.

\section{Interacción, tiempo y relaciones sociales}

El tiempo adquiere identidad social a partir de la variación de los acontecimientos sociales. El tiempo es social porque se impregna de contenidos sociales propios a la naturaleza de los cambios que lo generan. Dado además que los cambios sociales poseen momentos y ritmos diferenciados, los tiempos sociales serán también múltiples en sus unidades de referencia y escalas así como en su forma de progresión, por ejemplo, entre otros, lineal o dinámico. En consecuencia, el tiempo social es diverso en su contenido y secuenciación; incluso en un mismo entorno o situación de apariencia estable puede albergar diferentes tiempos sociales. En este sentido se opone al tiempo físico y/o a un tiempo abstracto unidimensional y reductor de los contenidos pero que en el mundo social pueden suponer variaciones reales. El tiempo social es, por tanto, poliédrico pues está sustantivamente vinculado a la naturaleza de los acontecimientos que lo generan. No se trata pues de una realidad homogénea o uniforme pues la naturaleza y los ritmos de tales acontecimientos son diversos y sus dinámicas no son necesariamente monótonas. Además, el tiempo social puede tener una connotación más individual o personal si nos reducimos a trayectorias de interacciones individuales o ser de naturaleza más colectiva. Incluso, el tiempo social puede ser anterior o concomitante a cualquier cronometría física del mismo. El tiempo cronométrico tiene pertinencia social si proviene de un consenso social aunque tenga su origen en la abstracción de una temporalidad vinculada a fenómenos físicos. (Elchardus y Glorieux, 1988). Al dar tal denotación al tiempo no negamos la existencia de otras pertinencias del mismo.

Veamos pues, casi en forma de propuestas sintéticas, el cómo y el porqué de dicha naturaleza social de tiempo comenzando con una breve puntualización sobre algunas de sus concepciones, a veces situadas en las antípodas teóricas. La temporalidad, en particular en perspectiva sociológica, puede contemplarse o desde una orientación objetiva y pragmática basada en la variación observable de los hechos sociales versus una orientación subjetiva e interiorizada, por la que los fenómenos sociales lo son en tanto que han sido aprehendidos internamente por los sujetos sociales. Por otro lado, la realidad y los cambios sociales pueden ser vistos o bien desde una perspectiva individual o bien desde una colectiva. Encontramos pues en estos dos principios clasificatorios una inicial tipología del tiempo social que se reflejan en los campos de la sociología. 
Los autores a los que se hace referencia a continuación representan, por ejemplo, polos opuestos en la identificación del tiempo social. De un lado, encontraríamos a Durkheim (1990: 14), Halbwachs (1994), Gurvitch (1962, I:51; 1969, II) y Marx (véase Elías, 1986, y Farrugia, 1999) que, aunque con diferencias importantes, no sólo dan al tiempo una identidad social con mayor o menor grado de homogeneidad o multiplicidad sino también objetivada y colectiva; y, de otro a Bergson (1889), Mead (1932, 1934) y Whitehead (1969) que dan al tiempo, primero, una mayor connotación fenomenológica y subjetiva en la manera de aprehender los fenómenos sociales, en Bergson; en la mayor centralidad dada a la interacción e intersubjetividad, en Mead; en la entidad sistémica a partir de la captación y relación macro-micro, en Whitehead. En cuanto a la dimensión colectiva versus la individual las diferencias son evidentes entre dichos autores. Lo que interesa resaltar con esta rápida incidencia en estos autores es mostrar cómo en la concepción del tiempo social convergen controversias de diferentes teorías sociológicas y/o filosóficas (véase Farrugia, 1999; Abbott, 2001).

La identidad social del tiempo proviene, como se viene afirmando, de los cambios observables en los fenómenos sociales. Pero dado que los cambios sociales se orginan en las interacciones entre agentes sociales, en ellas se ha de encontrar pues el germen de la identidad social del tiempo. Toda interacción que suponga una modificación de la naturaleza y apropiación de sus resultados debido a los recursos, representaciones, poder y estrategias de los sujetos introduce, pues, un principio y el origen de una nueva temporalidad social. Por ejemplo los cambios implicados en el nacimiento del primer hijo/a de una pareja, resultado interactivo nuevo dada la presencia de otro sujeto social que modifica estrategias, apropiación y distribución de recursos y tareas nuevas, supone el inicio de una temporalidad y referencia de 'medición' social diferentes, esto es, la del tiempo entre 'pareja sin hijo' comparado al de 'pareja con un hijo', al de 'pareja con dos'... La dimensión o identidad temporal, dada por la presencia de hijos en la familia, puede constituir la dimensión temporal fundamental que dé cuenta de la dinámica del ciclo de vida de una persona o de una pareja. Además puede superponerse o entrar en contradicción con otras diversas dinámicas temporales dada su multiplicidad, por ejemplo con la temporalidad que supone el campo profesional (López y Lozares, 2007). Así pues, dada la variedad de contenidos y ritmos sociales inherentes a las interacciones sociales, la naturaleza de los tiempos sociales es también diferentes (Lozares, López y Domínguez, 1998; Lozares y Verd, 2004; Lozares, López y Martí, 2004; Miguélez y Torns, 2000; Torns, 1994). La ausencia de hijos/as y los sucesivos nacimientos son 'momentos' que, como mojones, establecen orígenes de 
temporalidades de naturaleza social, en este caso relativamente homogénea como es el ciclo familiar, pero ello no evita que la emergencia de conflicto provenga de su choque con otras dimensiones temporales.

Según esta concepción los tiempos sociales, primero, no son 'medibles' por un tiempo abstracto cronológico sino por 'unidades de referencia y escalas' de contenido social. Además las temporalidades sociales, atendiendo a su lógica y proceso, pueden ser más o menos dilatadas e instantáneas, estables o inestables, equilibradas o desequilibrantes, clausuradas e incompletas; unas temporalidades serán lineales y otras complejas y dinámicas; unas serán monótonas, repetitivas o cíclicas y otras progresivas. El tiempo social, y sus temporalidades, participa pues de las polaridades y dualidades propias a las características de la variabilidad de las interacciones y situaciones que generan cambios sociales, en el nivel que sea.

El tiempo social, que adquiere su pertinencia en los procesos de interacción y cambio social, pasa por ello a ser un resultado y al mismo tiempo un recurso disponible para los sujetos sociales en vista a otra interacción. Precisamente porque el tiempo social es apropiable y apropiado se dan distribuciones diferenciales del mismo en las personas y en los grupos y contribuyen a generar entidades sociales personales y grupos sociales: el tiempo es pues una realidad social desigualmente distribuida en y por diferentes actores sociales (Wallemacq, 1988); esto es, el tiempo social es parte inherente de la estructura social. En este sentido el tiempo social se inserta en la estática y dinámica que se da entre interacción y estructura social participando e inscribiéndose así en los marcos y estructuras culturales y sociales (Sorokin y Merton, 1937). A su vez, como apropiación y recurso de los sujetos puede generar, desarrollar (o dinamizar) nuevas interacciones y estructuras (Elias, 1985).

Dentro de este proceso interactivo del que deriva su identidad, el tiempo es no sólo objetivación proveniente de la externalidad del cambio social sino también representación, proyecto y estrategia internalizada. Es no sólo recurso real y palpable sino también objeto del deseo y de apropiación para imaginarios de satisfacción, es decir en una realidad interna y subjetivizada.

Visto todo ello en perspectiva relacional, se ha de tener en cuenta que toda interacción social genera como resultado una relación entre los agentes que intervienen. Por ello la relación está impregnada del tipo y naturaleza del tiempo social correspondiente a dicha interacción. Como resultado de la interacción la relación pasa a ser también un recurso temporal para los agentes que se apropien 
de ella en vistas a las interacciones posteriores. De esta manera las relaciones sociales, con sus contendidos y ritmos temporales, se incorporan a la construcción de la estructura social y a su dinámica de cambio como componentes y factores básicos de la misma. Dada pues la contigüidad y ligazón entre interacción y relación, la temporalidad propia de los cambios y naturaleza de las relaciones sociales marcan también la temporalidad social. Por tanto, las temporalidades de los itinerarios socio-personales, como por ejemplo las del ciclo familiar, profesional, amical o del afectivo, etc., provienen de los diferentes cambios que aparecen en los itinerarios socio-personales pero también relacionales. Los itinerarios de las redes socio-personales pasan pues a ser reveladores sociales, no sólo en un sentido estructural sino también dinámico-temporal.

\section{La temporalidad social, la entrevista biográfico-narrativa y la dinámica de la red socio-personal: un modelo para el análisis y la interpretación}

En este apartado nos planteamos la cuestión del cómo, el porqué y hasta qué punto la entrevista biográfico-narrativa puede poner de manifiesto y ser un mecanismo de análisis pertinente de la naturaleza dinámica de las redes socio-personales y por ello del discurso que expresa. El objetivo consiste en presentar un modelo de configuración y construcción del relato biográfico como trayectoria socio-reticular de la persona entrevistada y de explorar y confirmar su potencial interpretativo como discurso, en el apartado 3.

En líneas generales el modelo consiste,

- primero, en concebir la trayectoria biográfica del entrevistado como conjuntos de entornos reticulares (contextos y estructuras de las relaciones personales que aparecen en el relato) y de examinar e interpretar dichos entornos o episodios, tanto como estructuras reticulares que condicionan o facilitan la interacción del individuo que como contribución del propio entrevistado a generar dichos entornos; esta primera premisa está en la base de la concepción o dimensión sincrónica del relato para cada entorno;

- segundo, en identificar la identidad y sentido de la dinámica de la red sociopersonal del Ego como una trayectoria temporal de relaciones, lo que genera la dimensión diacrónica del relato y

- tercero, en conjugar las diferentes estructuras reticulares y temporalidad(es) propia(s) de los entornos con la secuencia temporal de los mismos a partir de pasajes, que establecen el salto entre temporalidades. 
Los engarces y la comparación entre entornos, que son estructuras de redes sociopersonales, hacen confluir las estructuras sociales sincrónicas de la redes sociopersonales con la dimensión dinámica.

Como parece obvio, los principios, lógica, diseño y métodos propios de las redes sociales, y más concretamente del análisis reticular del discurso (Carley, 1997; Franzosi, 1994; Lozares, 2006; Lozares et al., 2003; Verd, 2005, 2006, 2007) están en la base de la perspectiva y metodología de este modelo.

\section{Las narraciones biográficas}

Las narraciones biográficas ocupan un lugar privilegiado en los estudios sociológicos. El análisis e interpretación de las mismas puede perfectamente identificar situaciones biográficas en la entrevista y analizarlas e interpretarlas en su sucesión temporal aunque no a partir de las relaciones o redes socio-personales como aquí se propone.

La narración biográfica se contempla, como se viene proponiendo, como conjuntos de acontecimientos (agente e interacciones) que se suceden en el tiempo. Cada conjunto está estructurado a partir de relaciones entre sus elementos o componentes poseyendo un cierto grado de homogeneidad de contenidos, funciones y naturaleza de sus agentes. Esto es, se trata de acontecimientos o entornos, que poseen una cierta coherencia y clausura temática que proviene de la naturaleza de las interacciones que albergan y los constituyen. Estos conjuntos están estruturados a partir de las relaciones que mantienen sus agentes. A su vez, dichos entornos están encadenados temporalmente con alguna lógica y dinámica narrativa, a través de la intermediación, también relacional, de determinados momentos, situaciones o pasajes claves que hacen de transición, encrucijada o puente entre los entornos. Estos pasajes también son relacionales. Diversos autores (Runyan, 1984; Wengraf, 2001), en los que no entramos, han optado por orientaciones similares a la pergeñada aquí aunque no necesariamente dentro de la perspectiva reticular.

\section{La conjunción de la sincronía y la diacronía como dinámica de la narración biográfica y de la trayectoria de la red socio-personal y tipos de conocimiento}

Los años 1980 y 1990 marcan el hito del inicio y de la eclosión de los estudios de las narrativas biográficas en sociología. Los análisis e interpretación de las narraciones se llevan acabo en función de sus características. Una de dichas características consiste (véase Labov y Waletsky, 1967; Lejeune, 1989; Adam, 
1992) en la descomposición de la narración en dos dimensiones básicas, una sincrónica y otra diacrónica. Esta dimensionalización guarda un gran paralelismo con la distinción que establece la ciencia cognitiva entre, por un lado, la memoria o conocimiento semántico por la que captamos e interiorizamos la realidad social de nuestro entorno dando sentido a lo que nos rodea en temporalidad sincrónica, lo que no quiere decir instantánea; y, por otro, la memoria o conocimiento episódico que está en la base de la percepción y asunción de la diacronía y de la sucesión temporal y, con ello, la dinámica de los acontecimientos. Esta segunda memoria hace referencia al conocimiento que proviene de experiencias vividas en el pasado, recodadas y revividas en el relato (Wheeler, 2000). Esta homología en la dimensionalización entre narrativa, biográfica en nuestro caso, y conocimiento refuerza más el modelo presentado: por un lado, lo que se viene denominando entornos interactivos, reticularmente estructurados, de la red socio-personal en una temporalidad relativamente clausurada corresponden a la dimensión sincrónica de las narrativas y a la memoria semántica como conocimiento y, por otro lado, la dinámica de la red socio-personal corresponde a la dimensión diacrónica de la narración y a la memoria episódica como conocimiento. Ambas perspectivas, que subyacen en la narración biográfica, están correlacionadas con el modelo presentado y con la aproximación del conocimiento esbozada. Ambas se entretejen

y combinan en la realidad del relato y en el conocimiento que lo captan e interpretan: de la conjugación de la dimensión sincrónica y de la dinámica y de las memorias semánticas y episódicas surgen, en la narración biográfica, los sujetos y entidades sociales del texto, las interacciones y relaciones, los entornos, episodios o dominios sociales y, globalmente, el discurso como entidad total y con sentido. El discurso narrativo, no es pues un conglomerado de unidades y categorías codificadas y clasificadas en diferentes tipos de estructuras sin tener en cuenta su propia lógica y dinámica temporal y un tipo de aproximación cognitiva, sino que sus unidades y componentes están relacionadas y estructuradas semántica y sincrónicamente desde la objetividad de la narración y desde el significado e intepretación del conocimento, por un lado, y, por otro, diacrónica y temporalmente relacionadas y articuladas también dentro de la objetividad y desde el sentido o dimensión espisódica del conocimento.

\section{EI modelo}

El modelo que se presenta consiste pues en un marco general adecuado para el análisis de las narraciones biográficas. El modelo articula, de una parte, la dimensión sincrónica constituida por entornos reticulares, constituidos a su vez por representaciones semánticas de la realidad interactiva y relacional de los mismos y, 
de otra parte, la dimensión diacrónica, con base también reticular, expresada en la representación episódica propia a la sucesión de dichos entornos. Este modelo se ha de concretar en otro algo más operativo sobre la dinámica de la trayectoria de las redes socio-personales narrativas del entrevistado.

Las relaciones socio-personales provienen de los vínculos que el Ego entrevistado establece en el relato, primero, con otras entidades de la narración como son otros individuos-personas, sujetos colectivos e institucionales, objetos y artefactos, etc. y, segundo, entre dichas entidades entre sí. Esta perspectiva es una de las posibles dentro del análisis reticular del discurso (Lozares et al., 2003).

Lo que se llamará Entorno Interactivo Situacional y Reticular (EISR, en adelante) consiste en las interacciones o relaciones estructuradas reticularmente entre agentes, objetos, entidades... que aparecen en la narración poseyendo un cierto grado de homogeneidad de contenido y funcional en sus interacciones o relaciones personales y con una cierta clausura socio-espacial y socio-temporal; anteriormente se ha venido denominando genéricamente entorno. El Ego, que es quien las genera a partir de su memoria semántica, está incluido en dichos EISR. Se corresponde con la dimensión sincrónica de todo relato.

Lo que se llamará Pasaje Narrativo consiste de los eslabones o vínculos relacionales (dado de nuevo por la narración del Ego) entre los EISR a través de las relaciones socio-personales entre Nodos de diferentes EISR. Proviene del conocimiento o memoria episódico-narrativa. Esta segunda cara da la orientación y dinámica temporal de la trayectoria de la red socio-personal.

Desde la perspectiva de la dinámica de las redes socio-personales en las narraciones, la vinculación entre los EIES por la mediación de los Pasajes Narrativos generan la progresión y el dinamismo del relato y dan pie, por tanto, a adoptar el modelo propuesto y los criterios metodológicos y métodos que aparecen en el apartado siguiente, 3. Más genéricamente, este modelo proporciona un procedimiento adecuado para el análisis e interpretación del texto narrativo bajo el prisma de la dinámica de las redes socio-temporales. Esta construcción de entornos y de sus relaciones dinámicas es decisiva para encontrar la o las líneas que dan coherencia y sentido al texto y discurso.

Este modelo tiene una base lingüística además de base narrativa y cognitiva señaladas: el interaccionismo, el lingüistico (Gumperz, 1982a, 1982b; Davis y Harré, 1992) y el simbólico (Goffman, 1974; Schiffrin, 1994); la pragmática 
lingüística (Austin, 1962; Searle, 1969, 1977); la teoría de la enunciación (Coulioli, 1990; Benveniste, 1966); y la etnografía del habla (Gumperz y Hymes, 1962).

\section{Los Entornos Interactivos Situacionales y Reticulares (EISR), los Pasajes Narrativos, las trayectorias y dinámicas de las red socio- personal}

En este apartado se trata de responder a las preguntas iniciales y comprobar, con su aplicación, la eficiencia del modelo anunciado en la perspectiva de la trayectoria de las redes socio-personales. Entramos pues en la configuración e identificación de los EISR ${ }^{2}$ y de los Pasajes Narrativos. Para ello se afinará la definición de dichos conceptos incluso de una manera más operativa y se dará cuenta del método adecuado de análisis a partir de una aplicación que muestre las posibilidades que ofrece la entrevista como mecanismo de análisis e interpretación de las redes sociopersonales y por ellas el discurso del relato.

\section{La formación de los EISR como dominios o campos de redes socio- personales}

Como hemos señalado precedentemente los Nodos de la red del Ego entrevistado son los agentes/actores (por ejemplo el propio ego, otros agentes personales que el ego, instituciones, organizaciones, etc.); realidades materiales o conceptuales, objetos o instrumentos, etc. ${ }^{3}$ que aparecen en el relato. La presencia y contenidos de los Nodos en el relato provienen de los declarados por el Ego entrevistado. Las Relaciones, parte constitutiva de la red, corresponden a las expresiones verbales de cada unidad mínima de análisis tomada como referencia de registro y significado. En nuestro caso, cada unidad mínima es equivalente a cada oración o proposición del texto. El entrevistado va desgranando y construyendo a lo largo del relato biográfico y en cada una de las proposiciones enunciadas múltiples y diferentes Nodos, interacciones y por tanto relaciones. En consecuencia, la primera operación consiste en dividir el relato en dichas unidades mínimas e ir relacionando los Nodos que aparecen en ellas a través y con el contenido de sus expresiones verbales correspondientes. Un mismo Nodo puede aparecer en diferentes proposiciones.

\footnotetext{
${ }^{2}$ La expresión EISR, Entornos Interactivos y Situacionales puede entenderse como diversas caras de un mismo prisma. Por El, Entorno Interactivo, se pone de manifiesto el lado estructural semántico y sintáctico, que puede traducirse en una red de interacciones dentro de una temporalidad y relaciones dadas por la interacción entre nodos; por ES, Episodio Situacional, se pretende evidenciar o resaltar el lado pragmático y situacional de tales Entornos; y por el ER la naturaleza relacional y reticular de los vínculos.

${ }^{3}$ La extensión de los Nodos más allá de los agentes-personas obedece a la exigencia de incluir en los EISR otros sujetos o entidades que también configuran o son parte de los mismos en tanto que realidades de agencia contextual con los que se relaciona el Ego. Con ello vemos el EISR al completo con todo lo que tiene una función condicionante o facilitador de las interacciones o relaciones personales.
} 
Un EISR es una parte del relato que contiene un conjunto de Nodos y Relaciones, en el sentido que venimos expresando, con un grado de contagio temático y de funcionalidad (por ejemplo, un texto narrativo referido a la escuela o a la familia, etc.) y con una cierta clausura marcada socio-espacial y socio-temporalmente por expresiones explícitas de 'lugares y tiempo' o de sus deícticos. Cada EISR guarda, pues, un grado mayor de homogeneidad de contenido y de funcionalidad interna así como de heterogeneidad con relación a los otros diferentes EISR. Adquiere, además, una estructura reticular a partir de las relaciones entre Nodos que aparecen en las unidades de referencia que pertenecen a dicho EISR. Los EISR ya reticulados son la expresión de la red socio-personal en el dominio o campo social que corresponden a cada EISR. La Figura 1 lo muestra en un caso hipotético.

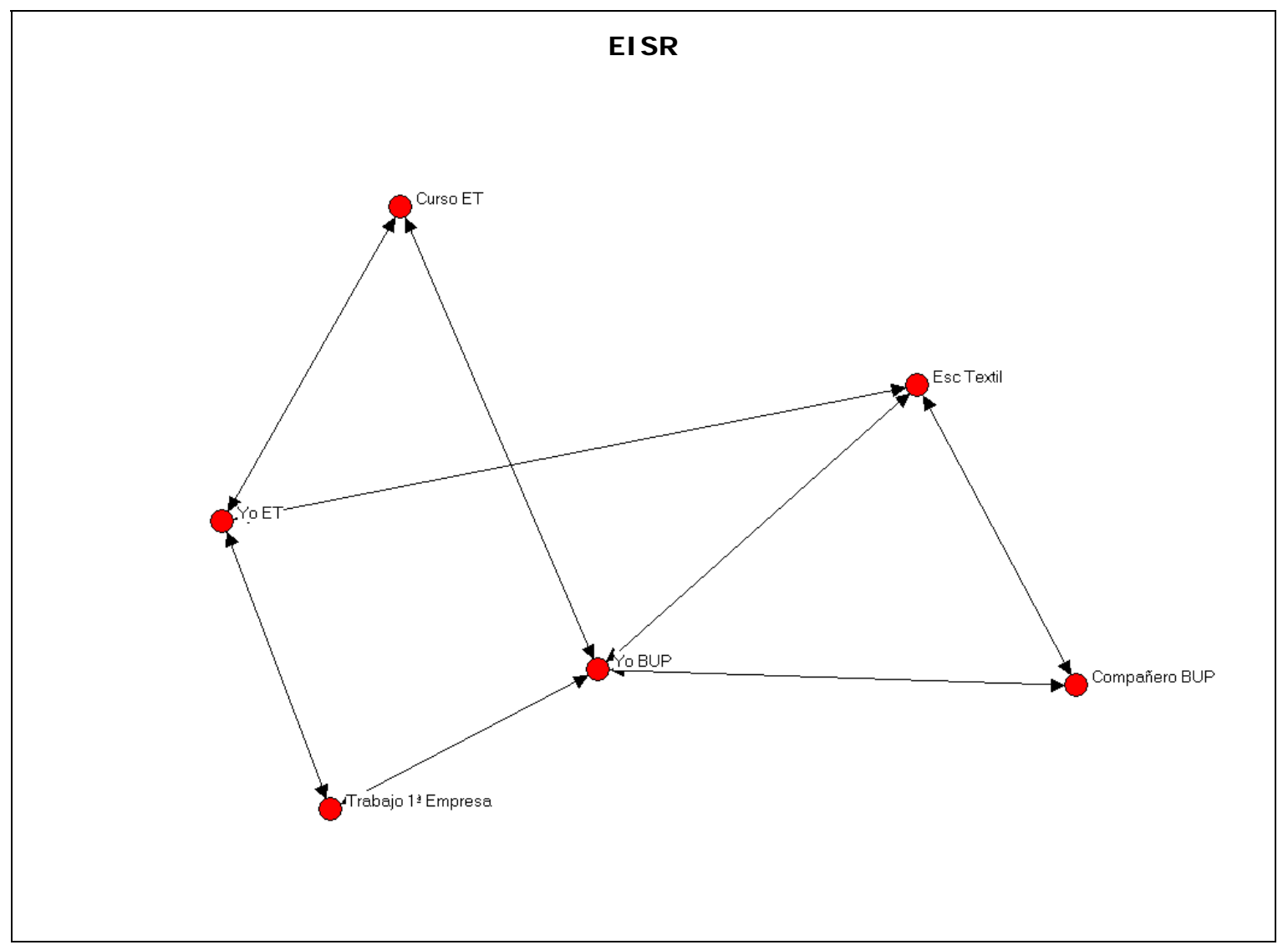

Figura 1. Un EISR.

Como se ha adelantado los Nodos de cada EISR pueden ser:

(i) un Yo genérico del Ego entrevistado o relator ${ }^{4}$

Además en la narración el Ego ya establece la red y la estructura que atribuye al conjunto de Nodos las relaciones que aparecen en los EISR.

${ }^{4}$ Se trata del Yo recapitulativo de la entrevista, el Yo que crea narrativamente los otros Yoes y los EISR correspondientes en la entrevista como parte esencial de la red socio-personal. 
(ii) un Yo que corresponde a cada EISR ${ }^{5}$

(iii) otros Sujetos individuales y colectivos: grupos, asociaciones, organizaciones, entidades administrativas, etc.

(iv) otras entidades de carácter más concreto, material o abstracto y conceptual que no son de naturaleza personal.

Además de la diversidad de Nodos que aparece en un EISR, puede darse también una cierta variedad de Relaciones o expresiones verbales en las proposiciones propias al EISR y en el conjunto del relato lo que exigirá una reducción clasificatoria de las mismas desde el punto de vista conceptual y operativo. Puesto que los EISR configuran identidades en su contenido, función, roles y objetivos genéricos (el entorno o campo de la universidad, de la familia, de la empresa, etc.) cada uno está caracterizado por poseer una identidad u homogeneidad temporal o temporalidad específica. Así pues un EISR es una entidad estructurada reticularmente entre Nodos de diversa índole dados por el relato del Ego, propios a dicho EISR; en su identidad se integra además su temporalidad propia. Es decir, se trata de una real construcción social del Ego entrevistado con todos sus ingredientes. La estructura y temporalidad propias a cada IESR puede ser contrastada o comparada con las de otros EISR. Estas temporalidades se suceden y ligan en el tiempo a partir de los Pasajes entre EISR.

\section{Los Pasajes narrativos como espina dorsal de la dinámica de las redes socio-personales}

Aunque dos EISR tengan identidades temporales y sociales diferentes, sin embargo pueden tener relaciones entre sí en el caso en que Nodos de cada uno de los EISR las mantengan. Por tanto, las relaciones que constituyen los Pasajes entre EISR expresan también la transición entre las correspondientes temporalidades. Por tanto, la sucesión sea de lineal o de interposición, superposición, etc. de los EISR vinculados por Pasajes a lo largo de todo el relato es lo que establece la dinámica de la red socio-personal, siendo dichos Pasajes marcadores del 'cambio horario o aduana socio-temporales' entre IOS EISR - se ha de recordar que los EISR son redes socio-personales. En el lenguaje de Goffman, los EISR pasan a ser unidades

\footnotetext{
${ }^{5}$ El Yo o del entrevistado se muestra de forma explícita en los enunciados de carácter modal. Aparecen también otros Yoes, atribuibles o propios de diferentes momentos EISR de la biografía relatada por el entrevistador: el yo de la escuela primaria, el de la universidad... Estos Yoes nacen en el relato y no se han de confundir con el Yo narrador o del entrevistado: el Yo entrevistado genera y habla de los Yoes propios a los EISR. Esta diferencia de Yoes es clave en la concepción del modelo y en la interpretación
} 
dramáticas dentro del 'drama' general del relato; por tanto en el discurso son unidades de referencia del discurso de tal forma que la relación entre ellas configuran una totalidad con significado propio a partir de su temporalidad (Goffman, 1987); en el de la lingüística cognitiva los EISR se aproximan a los 'frames' o marcos semánticos; y en el de White $(1992,1995)$ a los dominios reticulares. Es decir, los EISR son a su nivel formaciones socioculturales. Los Pasajes vinculan dichas formaciones que representan zonas del discurso más densas o centradas (cohesiva y/o estructuralmente). La misma identidad dada a los EISR conlleva que los Pasajes entre (o inter) dos de ellos sean menos densos que la densidad de dentro (o intra) de cada EISR, lo que no quiere decir que los Pasajes sean menos importantes o débiles; son importantes porque representan la continuidad temporal, o posible ruptura, de los diferentes EISR; en todo caso simpre representan un punto de inflexión en el discurso reticular. En el ejemplo que comentaremos en la Figura 2 se muestran articulaciones posibles entre EISR. LoS segmentos entre ellos son los Pasajes narrativos entre Nodos de diferentes EISR. La figura, en conjunto, manifestaría la dinámica de la red socio-personal.

\section{Un ejemplo ilustrativo de la aproximación propuesta}

En esta ejemplificación no damos cuenta del detalle del proceso de codificación del texto, ni del análisis de las unidades elementales como son las proposiciones para extraer los Nodos y sus Relaciones (véase Lozares, 2006) ya que se trata sólo de mostrar que la entrevista biográfico-narrativa constituye una fuente de información privilegiada y, su análisis o interpretación, un método adecuado para estudiar la dinámica pragmática, contextualizada y reticular de una red socio-personal basada en las temporalidades y dinámicas propias implementadas por el mismo narrador y no por el analista ${ }^{6}$.

\section{EI relato del EISR de la Escuela de Artes y Oficios y los primeros pasos del análisis}

El Cuadro 1 recoge exclusivamente todas las referencias que aparecen en todo el texto de la entrevista narrativo-biográfica del paso por la Escuela de Artes y Oficios (EAO), del entrevistado, en este caso, un joven trabajador en una empresa de

como redes socio-personales. En este sentido hay tantos Yoes como EISR. Los diferentes Yoes intervienen en cada EISR y pertenecen a la estructura de la red socio-personal de cada uno de ellos.

6 Tampoco entramos en las tipologías posibles de relaciones distintas y ricas que se dan entre los Nodos debido a las variadas codificaciones posibles de las expresiones verbales. Para esta ilustración sólo elegiremos, para dar cuenta mejor de los procesos dinámicos, las expresiones verbales (o relaciones entre Nodos) que muestran relaciones fácticas (sin entrar en subclasificaciones de las mismas) dejando de lado pe. las cognitivas y otras clasificaciones que enriquecen la interpretación de la dinámica de las redes socio-personales.. 
tinte. La EAO configurará pues un EISR, con sus agentes, relaciones, etc., que es el objeto de esta ejemplificación. En este texto aparecen además otros Nodos de otros posibles EISR que mantienen relación con el de la EAO, como el Medio Familiar, la Primera Empresa y la Segunda Empresa, los Hobbies y las Amistades.

La primera operación, dentro del proceso de análisis, consiste en segmentar el texto en unidades mínimas de interacción, es decir, en las proposiciones que aparecen en el texto. Esta segmentación y la atribución de un significado denotado sin ambigüedad a cada una de las unidades que provienen de dicha segmentación, se llevan a cabo a partir de una lectura atenta, repetida e interpretativa del texto. Dichas unidades se van asignando a los correspondientes EISR que van surgiendo, de manera constructiva en un análisis inicial y elemental de la entrevista. Aunque los criterios de delimitación de los EISR sean los de máxima densidad y clausura temáticas, sin embargo, como se ha sugerido, son necesariamente abiertos entre sí (véase la figura 2$)^{7}$. Las operaciones siguientes consisten en identificar los Nodos en dicho texto y sus Relaciones.

Bueno, un compañero de clase, del Instituto me lo comentó. Mira, allí, enfrente del club de natación, la escuela de Arts i Oficis y allí, bueno fui, pregunté, me informé y me apunté, hice el curso y al final del curso, pues, incluso antes de acabar el curso ya empecé a trabajar. Yo le hice caso. Por eso para mí el curso de 3o BUP fue importante. Así pude entrar en la EAO. Mientras hacía 3o de BUP hice también los cursos de la EAO. Con la entrada en la EAO para mí fue ya como trabajar en el textil.

Al hacer los cursos de los estudios de la EAO me di cuenta que los estudios de BUP servían para los estudios de la EAO en lo que es cultura y esas cosas. En la escuela a medida que pasaba el año iba adquiriendo más confianza en mí mismo y al final todo se me dio muy bien. Estos estudios y cursos los hice muy bien, al año ya estaba trabajando en la primera empresa.

Los estudios en la EAO se me dieron bien. Desde el momento que me enteré en el BUP de los cursos de la EAO por un compañero mi objetivo fue conseguir hacerlos. Estos estudios fueron la base teórica tanto para la primera empresa en la que trabajé como para la que trabajo ahora. Si no es por dichos estudios no entro en la primera empresa y es que la Escuela además te encontraba trabajo.

Los profesores de la escuela tienen influencia en la colocación de los alumnos en las empresas del textil de la comarca pues son los que han seguido los estudios de cada uno, te orientan, informan a los alumnos e intervienen luego en el momento de la selección de los alumnos...

El gremio de la industria textil de la comarca también es importante en la selección de los alumnos y en la contratación en las primeras empresas pues son los del patronato de la Escuela y la Escuela está para preparar gente para sus empresas. En todo esto de encontrar trabajo y que las empresas te llamen me parece que interviene también la dirección de la escuela.

\footnotetext{
${ }^{7}$ Criterios adicionales para establecer los EISR son, por ejemplo, su coherencia temática y funcional, un grado relativo de autonomía, la cobertura institucional (familia, amistades, empresa, escuela...), los marcadores que se explicitan o los deícticos que circunscriben los espacial y tiempos sociales.
} 
Casi al final del curso, la primera empresa me hizo un contrato para entrar a trabajar en ella. Lo hizo por medio de otra empresa de contratación. Un día me llamó, fui a Barcelona a los locales de esta Empresa y me hizo la entrevista. En la entrevista te hacen tests de capacidades y te preguntan sobre lo que has estudiado y sobre los intereses del trabajo.

Cuadro 1. Texto de la entrevista referido el EISR de la Escuela de Artes y Oficios (EAO) del Textil

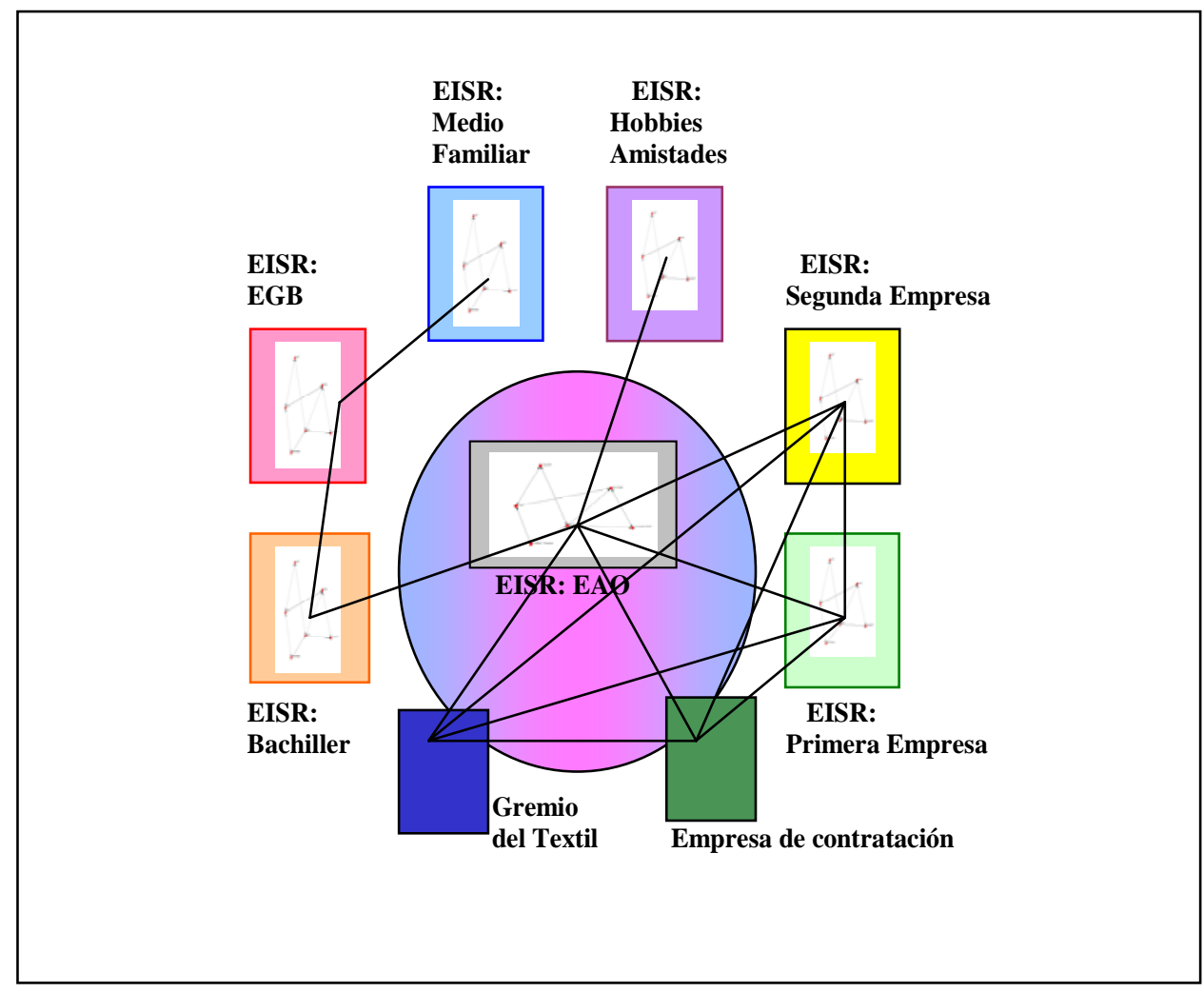

Figura 2. Imagen de los diversos EISR del relato.

I dentificación, clasificación y análisis de los Nodos de cada EISR de la Escuela de Artes y Oficios (EAO) como elementos de la red-sociopersonal del entrevistado

Se trata de identificar, clasificar y analizar los Nodos del texto, sean los propios al EISR de la EAO o de otros EISR pero que mantienen relación con el primero. La clasificación que aparece en el Cuadro 2 se refiere pues a la naturaleza o identidad de los Nodos de la EAO del Textil junto a su codificación: agentes personificados, colectivos o entidades, nodos concretos o abstractos o que indican procesos 0 estados. Aparece en vertical la clasificación de los Nodos según su naturaleza y envergadura social y, en horizontal, según la relación que mantienen con la EAO: los propios a la EAO; los de otros EISR diferentes de EAO pero en relación con EISR de la EAO; los que son mediación o puente, Pasajes, entre la EAO y otros EISR; y el 
Nodo del Yo entrevistado ${ }^{8}$. Este tipo de clasificación, de doble entrada, es de gran interés informativo e interpretativo pues introduce, además de los Yoes personales, otros más institucionales, colectivos, en realidad contextuales, con relación al Yo personal que se cruzan y comparan con la pertenencia a diferentes EISR, el propio al EAO y otros. En rojo intenso los Nodos que son los que serán tomados en cuenta en este ejemplo por aparecer vinculados con verbos que expresan relaciones fácticas, como veremos más adelante; los otros están presentes en otros tipos de relaciones no tomadas en cuenta en la aplicación que se hace.

\begin{tabular}{|c|c|c|c|c|}
\hline & $\begin{array}{c}\text { Propios al EISR de } \\
\text { la EAO }\end{array}$ & Otros EISR & Pasajes & $\begin{array}{l}\text { Propios al YO } \\
\text { entrevistado }\end{array}$ \\
\hline $\begin{array}{c}\text { Yoes del } \\
\text { entrevistado }\end{array}$ & YEAO : YO EAO & Y3BUP :Yo 3ㅇ BUP & $\begin{array}{l}\text { C3BUP : Compañero } \\
\text { de 3 BUP }\end{array}$ & $\begin{array}{ll}\text { YENT } & : \text { Yo } \\
\text { Entrevistado } & \end{array}$ \\
\hline $\begin{array}{l}\text { Grupos o } \\
\text { colectivos }\end{array}$ & $\begin{array}{l}\text { PEAO: Profesores } \\
\text { EAO } \\
\text { AEAO: Alumnos EAO } \\
\text { DEAO: Dirección EAO }\end{array}$ & & $\begin{array}{l}\text { GRTX:Gremio textil } \\
\text { de Empresarios } \\
\text { Comarca }\end{array}$ & \\
\hline $\begin{array}{l}\text { I nstituciones u } \\
\text { organizaciones }\end{array}$ & I EAO: InstituciónEAO & $\begin{array}{l}\text { 1 aETX: 1a Empresa } \\
\text { textil del } \\
\text { entrevistado } \\
\text { 2äETX: } 2 \text { a Empresa } \\
\text { textil del } \\
\text { entrevistado } \\
\text { EGTX: Empresas } \\
\text { del GT }\end{array}$ & $\begin{array}{l}\text { EC1ET: Empresa } \\
\text { Contratación para la } \\
\text { inserción en la 1a } \\
\text { 1ET }\end{array}$ & \\
\hline Cursos, Estudios & $\begin{array}{l}\text { EEAO: } \\
\text { cursos de la EAO }\end{array}$ & $\begin{array}{l}\text { EBUP: } \quad \text { Estudios, } \\
\text { curso de BUP } \\
\text { ESTD: Estudios }\end{array}$ & & \\
\hline Procesos & & & $\begin{array}{l}\text { I S1ET: Inserción } \\
\text { selección 1a ET } \\
\text { I ATX:Inserción } \\
\text { Alumnos en el Textil }\end{array}$ & $\begin{array}{l}\text { TTEX :Trabajo } \\
\text { en Textil }\end{array}$ \\
\hline $\begin{array}{c}\text { Estado personal, } \\
\text { cognitivo... } \\
\text { Competencias. } \\
\text { J uicios o valores }\end{array}$ & & & & $\begin{array}{l}\text { BIEN:Bien } \\
\text { Bueno } \\
\text { BTEO: } \\
\text { teórica } \\
\text { CAPAC: Capacidad } \\
\text { CONF : Confianza } \\
\text { I MPO : Importante } \\
\text { I NTE: Interés }\end{array}$ \\
\hline
\end{tabular}

Cuadro 2. Identidad y clasificación de los Nodos según propios a la EAO o en relación con la EAO y según su naturaleza y envergadura ${ }^{9}$

Este EISR de la EAO es singular, primero, por su apertura a otros EISR diferentes a la EAO ya que sólo aparecen un $1 / 4$ de Nodos propios con respecto a otros Nodos (Yoes o no), relacionados con él, pero de otros EISR; segundo, por su poder de

\footnotetext{
${ }^{8}$ El Nodo del Yo del entrevistado se refiere a Ego del entrevistado que produce la netrevista en el momento y situación de la llevarse a cabo la misma. En este Nodo el Yo Entrevistado o narrador es el de un sujeto que se 'sitúa fuera del relato', que cuenta y genera otros Nodos, acontecimientos y resultados y además hace valoraciones, dar opiniones, etc.

9 El cuadro expresa también los contenidos de los nodos de la red del EISR de la EAO. La relativa abundancia de siglas que identifican nodos puede hacer algo engorroso su seguimiento. Con todo, el texto es lo suficientemente corto como para que aún se puedan guardar los contenidos de las siglas en la memoria inmediata del lector. De todas maneras el cuadro 2 siempre puede servir de referencia para dichos contenidos. Para su mejor manejo se ha tratado de expresar en el texto al lado de la sigla su contenido para no tener que volver la Cuadro 2.
} 
intermediación global de la EAO con relación a otros EISR dado los Nodos que hacen de Pasaje; tercero, por el rol importante que tienen los Nodos personales, colectivos e institucionales. Cuando se lleva a cabo el análisis global de la entrevista, el EISR de la EAO, en tanto que EISR, tiene, como ya se constata en el cuadro, una función importante como transición o encrucijada en el relato de la vida laboral del entrevistado (ver Figura 2).

\section{La identificación y codificación de las Relaciones entre Nodos}

Las Relaciones entre los Nodos provienen, como hemos indicado, de las expresiones verbales de las proposiciones en que aparecen los Nodos. Son la manifestación y resultado de las interacciones, de todo tipo, que suponen y procuran las expresiones verbales. Estas Relaciones (o interacciones) que se dan en el relato, están también en el origen de la temporalidad de EISR de la EAO. Así los Nodos y sus relaciones forman un enjambre reticular, temporal y socialmente estructurado, que configura la red socio-personal del ego en dicho entorno. Pero, al no poder mantenerse toda la variabilidad observada de todas las expresiones verbales que aparecen, se hace necesario pasar por un proceso de clasificación y reducción en función de los objetivos de la investigación. Para efectos de la ilustración que se pretende sólo se usan las expresiones verbales (Cuadro 3) que significan contenidos fácticos y serán tomados por tanto como una sola Relación que vincula, bajo esta concepción fáctica, los Nodos de la EAO y los Nodos de otros EISR que tienen relación con ellos. ${ }^{10}$ Estas Relaciones fácticas se refieren a expresiones verbales de acciones/ interacciones realizadas por los sujetos o agentes (Nodos) que son externalizables por diferencia a otras que, por ejemplo, se pudieran referir al conocimiento o estados cognitivos internos del entrevistado. De esta manera se configura la red socio-personal del entrevistado en la EAO, su estructura y su temporalidad en el conjunto de la entrevista; las relaciones con Nodos de otros EISR distintos al de la EAO marcarán transiciones y por tanto la dinámica de las redes socio-personales en el conjunto de los EISR de su relato.

\footnotetext{
${ }^{10}$ Además de la clasificación general de las Relaciones fáctica v. cognitiva, dentro de la primera como de la segunda se puede establecer diferencias de verbos-relaciones según tipologías que expreses diferentes contenidos fácticos o cognitivos o diferentes procesos fácticos o cognitivos. Otros principios de clasificación pueden ser entre verbos modales o no modales; entre expresiones que representan igualdad o desigualdad, o causalidad como argumentaciones, etc. Las clasificaciones usadas son próximas al Análisis Proposicional del Discurso (Ghiglione, 1982; Ghiglione y Blanchet, 1991; Harvatopoulos et al., 1992: 96-98) y también a otras existentes en antropología cultural y la psicología cognitiva.
} 
Aceptar, apuntarse, buscar/encontrar, comentar, contratar, convocar, empezar, entrar, formar, hacer/ realizar, hacer caso (seguir el consejo/acepta), influir, informar, iniciar, intervenir, ir, llamar, orientar, preguntar, preparar, realizar, reparar, resultar, seguir estudios, servir para trabajar, valorar (de hacer tests)

Cuadro 3. Verbos fácticos del texto que aparecen en el EISR de la EAO.

Orientaciones para el análisis de la estructura de la red socio-personal del entrevistado en cada EISR, concretamente, de la EAO y de su temporalidad y dinámica.

Veamos en este apartado cómo el modelo propuesto posibilita la estructuración del EISR de la EAO a partir de las Relaciones entre Nodos, la entrada en su temporalidad propia y la puesta de relieve de los vínculos o con otros EISR, es decir, con otras estructuras o dominios semánticos y con sus temporalidades. Las figuras que vienen a continuación expresan las diferentes posibilidades para el análisis y la interpretación.

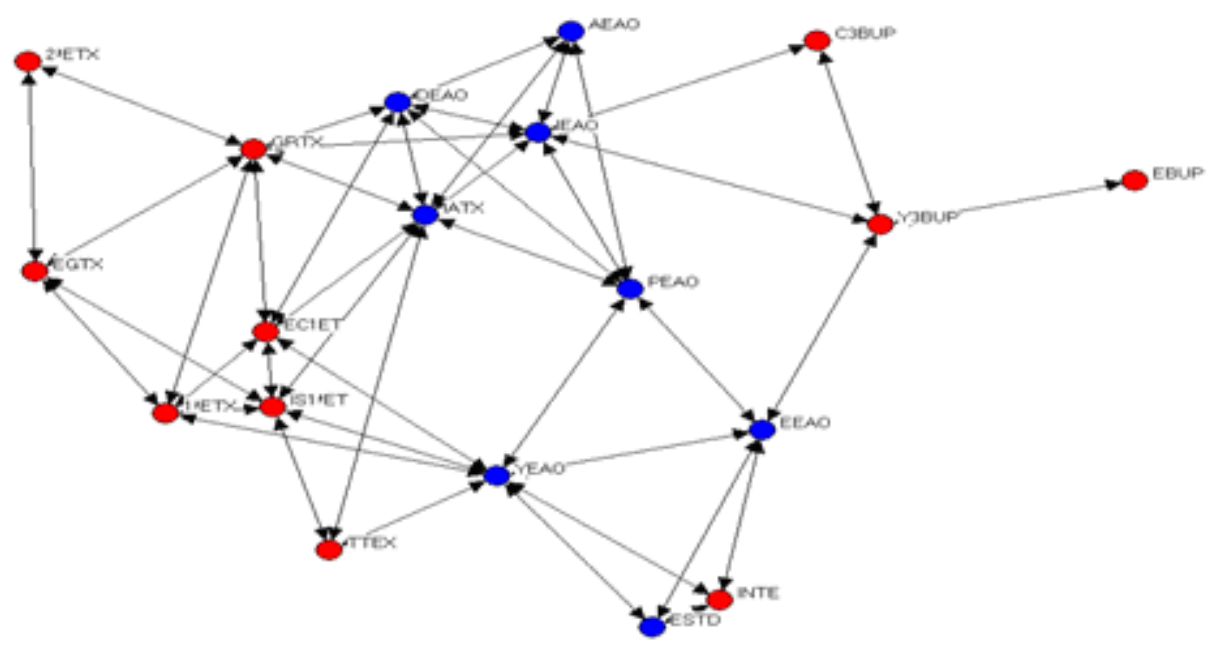

Figura 3. Estructura de los Nodos propios a la EAO y con los de otros EISR

Esta Figura 3 (además de criterios e indicadores propios al análisis de Redes Sociales) permite analizar la estructura de la red socio-personal del Yo del EISR de la EAO (YEAO) por las relacones entre los Nodos propios a este entorno (en azul) y en el conjunto de una red más amplia formada por los propios de la EAO y de otros entornos que están en contagio con él (rojo). No entramos aquí en el contenido de dicho análisis que se puede o inferir gráficamente o por medio de indicadores de Redes Sociales. 
La Figura 4 (además de todos los posibles análisis realizables por Redes Sociales) permite analizar la estructura de la red socio-personal de la EAO considerando los Nodos según su diferente naturaleza y envergadura social y contextual a fin identificar de manera más certera y de enmarcar más globalmente la naturaleza social del red del Ego y su posición y relaciones en el conjunto, más allá de sus redes exclusivamente vinculadas a unidades personales. La naturaleza de los Nodos es de diversa índole: personales, en rojo; colectivos o grupales, en azul; institucionales, en verde; entidades empresariales, en amarillo; y realidades más abstractas o procesos, en rosa. Vemos pues la estructura de las Relaciones sociopersonales con Nodos de diferente identidad social. Puede combinarse con los resultados del análisis precedente que hace la distinción entre Nodos propios a la EAO y los propios a otros Entornos, aquí los del BUP, por un lado, y, por otro, la 1 $1^{\underline{a}}$ Empresa.

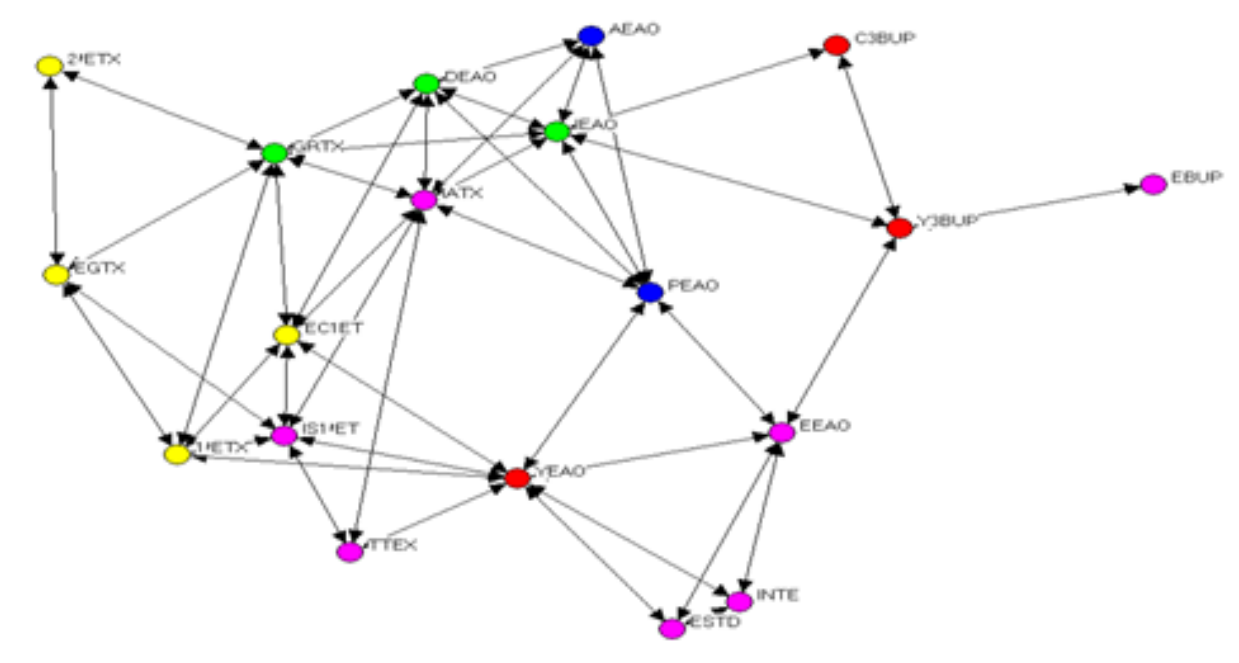

Figura 4. Estructura de la red socio-personal según naturaleza y envergadura de los Nodos.

La Figura 5 (y su posible análisis por indicadores de las Resde Sociales) permite estudiar los Pasajes (en azul) entre el EISR de la EAO: por un lado, con el EISR del BUP a la derecha, por medio del C3Bㅡ, un Compañero de BUP; y, por otro, con el EISR de la 1a Empresa del Textil por medio del GRTX, Gremio del Textil, de la EC1aET, Empresa de contratación del Textil y por la IS1aET, Inserción y Selección en la 1a Empresa del Textil. Son estos Pasajes los que hacen de intermediación entre el EISR en cuestión, el precedente, el BUP, y el siguiente, 1a Empresa del Textil. Marca la frontera pero también el paso o viaducto entre la estructura de la red socio-personal estudiada y las contiguas. Por tanto juegan un rol (causal o por mecanismos) de cambio entre dichas estructuras y también como veremos entre temporalidades diferentes. 


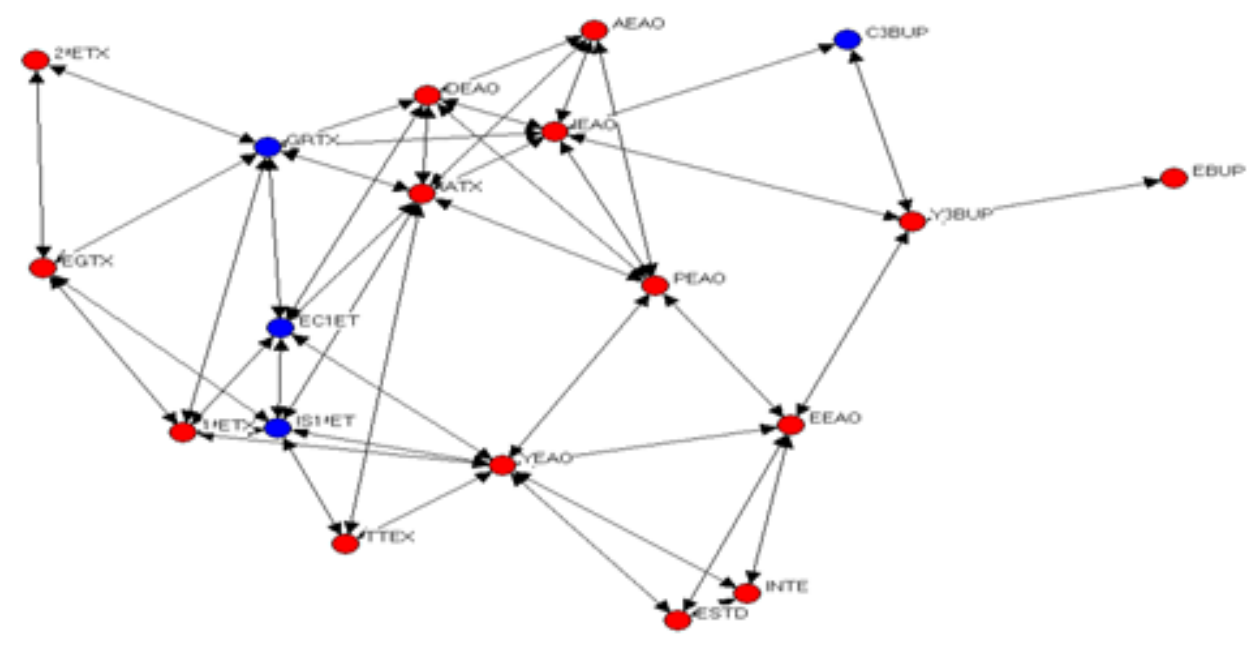

Figura 5. Los Pasajes entre el EISR de la EAO y los EISR contiguos

La conjunción de los tres análisis precedentes, si se hiciera para todos los EISR de la entrevista, nos permitiría (i) comparar las estructuras (tipos de Nodos, posiciones,...) de todos los EISR de la narración, esto es, redes socio-personales del entrevistado, en momentos distintos del ciclo de su vida (es decir sus cambios); (ii) las relaciones y Nodos de Pasaje, esto es, las circunstancias, azarosas o deterministas, causa o mecanismos de los cambios.

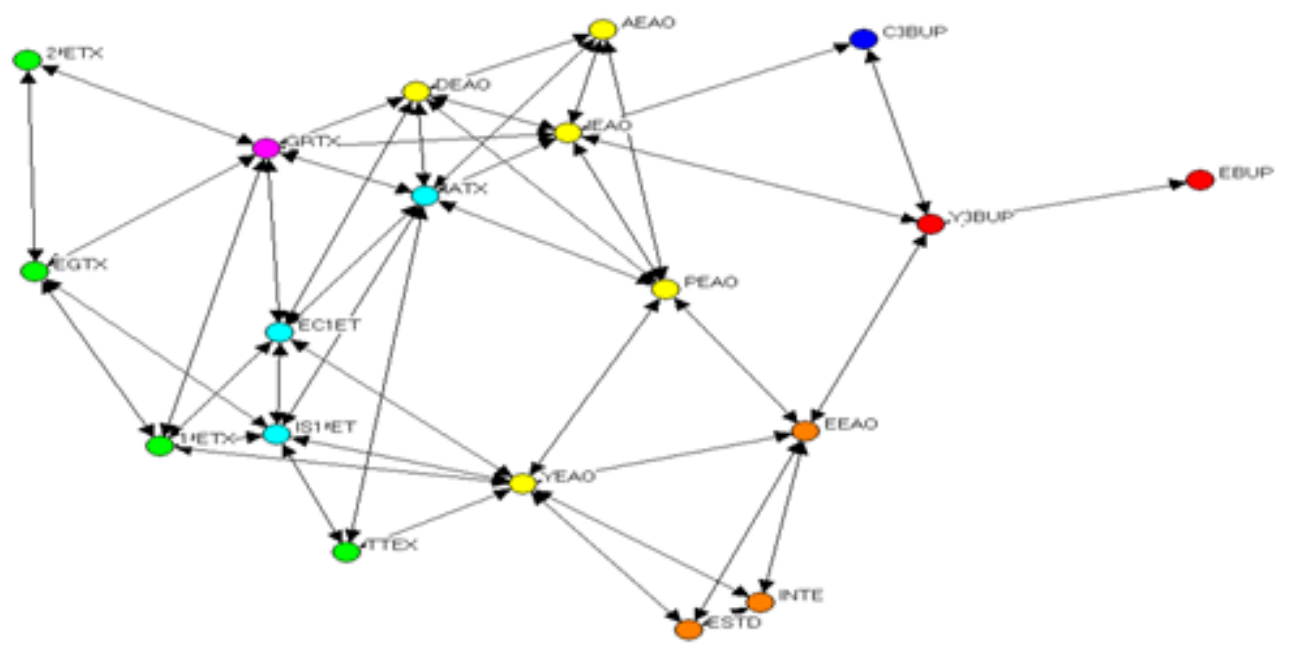

Figura 6. La evolución temporal. 
La figura 6 expresa, de derecha a izquierda, la evolución del tiempo cronológico. Sin embargo, en dicho tiempo, se generan otras temporalidades interactivas y relacionales, y por tanto sociales, propias a los diferentes EISR: de la temporalidad del BUP (rojo) se pasa, por medio del Pasaje del Compañero de 3o de BUP (azul fuerte) al EISR de la EAO (amarillo, ocre y alguno azul claro) y, de nuevo, por los intermediarios (azules claros y rosa) se aboca al EISR de la Empresa (verde). Son momentos sociales que se interponen o se suceden o van en paralelo etc. Se puede por tanto analizar cómo es la sucesión de los EISR, los acontecimientos, mecanismos, naturaleza de las temporalidades, etc., es decir, su dinámica.

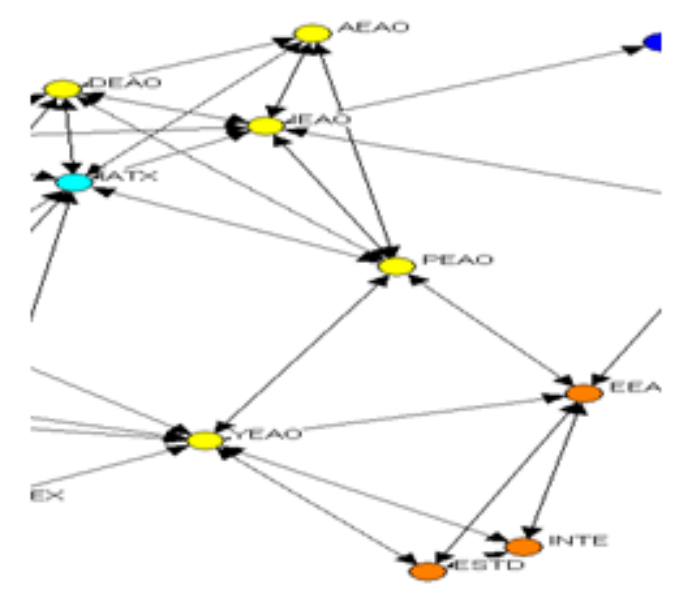

Figura 7. La temporalidad de la EAO.

La Figura 7 está recortada expresamente a partir de la Figura 6 para visualizar mejor los Nodos y Relaciones exclusivamente pertenecientes al EISR de la EAO. La temporalidad de este EISR puede contemplarse como una temporalidad única para todo la EAO pero también puede subdividirse, sin romper la unidad anunciada, en tres sub-temporalidades que se superponen parcialmente, lo que da la especificidad de la EAO: (i) la de los estudios que se llevan a cabo durante el año, temporalidad pautada y previsible (amarillo junto a ocre), (ii) la propia a la dirección de la escuela y su funcionamiento (amarillo y ocre) y (iii) la del proceso de inserción laboral (amarillo y azul claro). Lo importante a señalar es que la temporalidad del EISR de la EAO no es equivalente a la del tiempo cronológico. Se trata de una identidad temporal constituida por la conjuncion o composición de tres temporalidades sociales, objetivas y posiblemente también interiorizadas por el EGO de la EAO, pero que se evidencian en y por la Red socio-temporal siendo como son parte de la misma. Todas estas reflexiones sobre el EISR de la EAO nos acercan más a identificarlos como 'frame' semántico. 
La Figura 8 representa el Análisis de Escalamiento Multidimensional (AEM) de los Procesos Fácticos (o sea de la red del EISR de la EAO y, por tanto, de las redes socio-personales y temporales). A pesar de que este resultado gráfico es similar al de las figuras anteriores, lo que interesa recalcar aquí es que proviene de la aplicación del método del AEM; es decir, que los ejes tienen sentido en cuanto que son ejes o dimensiones del espacio vectorial de las relaciones en un EISR. El resultado es que el eje horizontal representa el desarrollo cronológico (aunque en el sentido invertido de derecha a izquierda). Se observa sorprendentemente por lo inesperado, pero también satisfactoriamente por las consecuencias, que el eje horizontal, es precisamente el del desarrollo cronológico de las temporalidades sociales de cada EISR y dentro de la EAO. Sobre dicho eje se superponen otras temporalidades con otras lógicas. El eje perpendicular, independiente del anterior, parece evidenciar la naturaleza de unos Nodos más grupales y/o institucionales en la parte superior, al menos en el EISR de la EAO, mientras que la inferior refleja más el proceso personal del EGO. Las dos dimensiones que aparecen, la primera, dando un sentido temporal al proceso al clasificar los subprocesos según la fase de su realización así como las transiciones con otros EISR y, la segunda, en vertical, que pone de manifiesto los diferentes tipos de actores/ agentes, de su tipificación y de su actividad según EISR diferentes es un buen clasificador-resumen del conjunto de la estática y dinámica del EISR examinado.

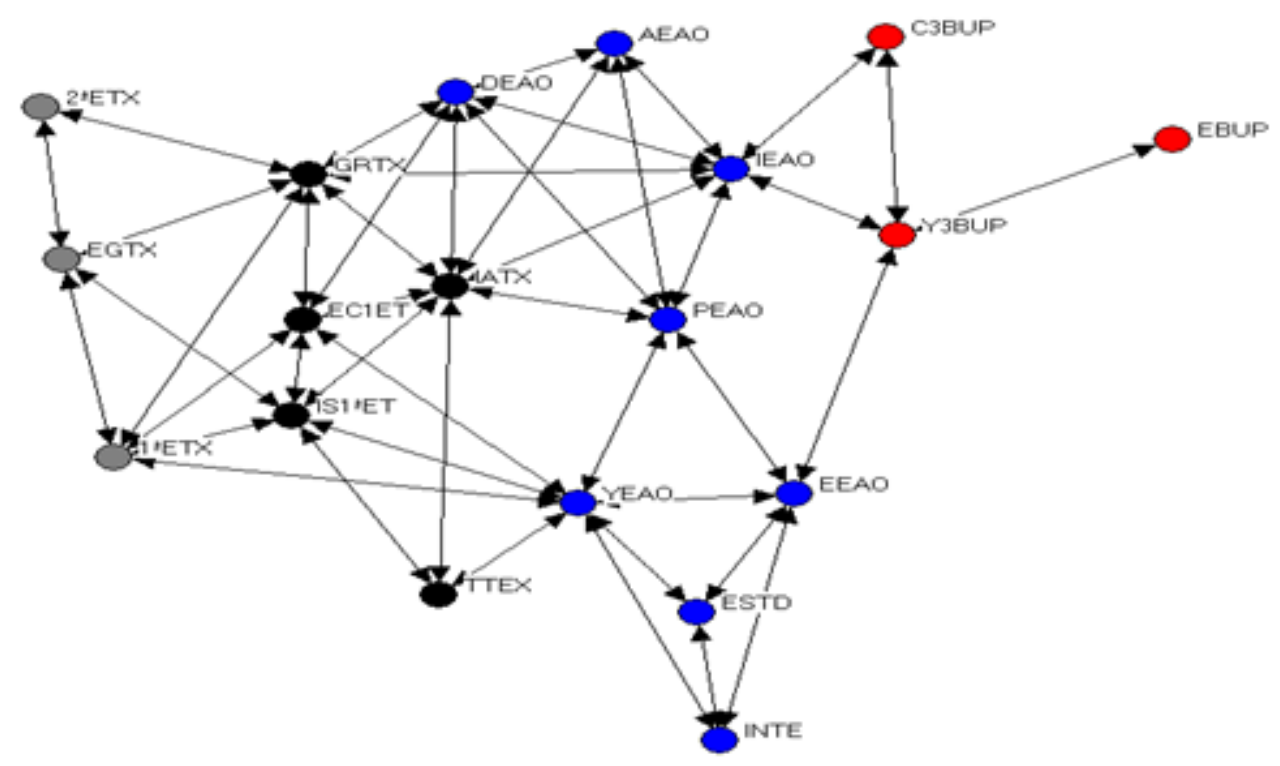

Figura 8. La temporalidad dada por el método del Escalonamiento Multidimensional. 


\section{Conclusiones}

La intención de este artículo consistía en evidenciar la adecuación del modelo y método presentado para el análisis e interpretación de la dinámica de las redes socio-personales. No se ha mostrado ni el análisis completo de una entrevista ni el análisis comparativo de varias lo que hubiera añadido más fuerza ilustrativa y argumentativa a la propuesta. Sin embargo el análisis realizado de una parte de una entrevista ofrece los elementos suficientes para poder corroborar tal adecuación. El objetivo del artículo ha consistido en hacer palpable hasta qué punto la entrevista narrativo-biográfica proporciona un conjunto y tipo de informaciones adicionales insustituibles que permiten una interpretación de la dinámica de las redes socio-personales tanto desde le perspectiva social como temporal y ellos desde una visión global y situacional.

A la ventaja genérica que ofrece el método de entrevista de no imponer previamente ningún tipo de temporalidad, relación o características de los nodos del Ego se añaden otras que se recogen ahora esquemáticamente pues se han expresando paulatinamente a lo largo del artículo.

La construcción de los EISR, primero, en tanto que relaciones socio-personales entre nodos sociales diversos, hace posible un análisis semántico estructural y social de la red del Ego en su paso por los diferentes ámbitos, campos o entornos del ciclo de su vida (o de otra temporalidad); segundo, da pie a un análisis más contextual, situacional y pragmático de las redes socio-personales; tercero, permite estudiar la propia temporalidad de EISR, en el sentido de que pueden darse en su interior distintos tipos de procesos que pueden marcar temporalidades diversas dentro del mismo EISR; y, cuarto, la toma en cuenta de los diversos EISR hace posible un estudio comparado entre ellos.

Lo que hemos denominado Pasajes entre EISR, primero, restablece la/s trayectoria/s global/es de las redes socio-personales en el ciclo de vida estudiado; $y$, segundo, ponen en evidencia los mecanismos de paso entre etapas de vida, EISR, (o del día) desde una posible perspectiva causal por mecanismos.

Por las articulaciones entre EISR y Pasajes se reconstruyen, desde la perspectiva de red socio-personal, las trayectoria o trayectorias del ciclo de vida considerado, lo que, primero, da paso a estudiar sus características, desde luego de contenido, pero también más formalmente como por ejemplo, linealidad o superposición de trayectorias según las formas de articulación entre EISR y Pasajes; continuidad o ruptura; unidireccionalidad o retroacción y/o bucles... y, segundo, dicho tipo de 
análisis sería de gran fecundidad interpretativa en el caso de comparar las dinámica de las diversas redes socio-personales que surgen en distintas entrevistas.

Por fin, una adecuada, inteligente, más o menos múltiple y/o multinivel de la codificación de las relaciones entre nodos, esto es, de las expresiones verbales, posibilita focalizarse o limitarse, en los contenidos de las redes socio-temporales, o a una gran simplicidad (un sólo contenido, como por ejemplo, el fáctico) o extenderse a muchos y diversos contenidos.

\section{Bibliografía}

Abbott, A. (2001). Time Matters. Chicago/London: The University of Chicago Press.

Adam, J. M. (1992). Les textes: types et prototypes. París: Nathan.

Austin, J. L. (1962). How To Do Things With Words. Oxford: Clarendon Press.

Benveniste, E. (1966). Problèmes de linguistique générale. Paris: Gallimard.

Bergson, H., (1889). Essai sur les données immétiates de la conscience. Time and Free Will. London: Allen Unwin.

Bidart, C., Degenne, A. (2005). "Introduction: the dynamics of personal networks". Social Networks, 27: 283-287.

Bidart, C., Lavenu, D. (2005). "Evolutions of personal networks and life events". Social Networks, 27: 359-376.

Carley, K. (1997). "Network text analysis: The network position of concepts". En Carl W. Roberts (ed.): Text Analysis for the Social Sciences: Methods for Drawing Statistical Inferences from Texts and Transcripts. Mahwah, New Jersey: Lawrence Erlbaum.

Coulioli, A. (1990). Pour une linguistique de l'énonciation. París: Ophrys.

Davies, B., Harré R. (1992). "Positioning the discursive production of selves". Journal for the theory of social behaviour, 20:43-63.

Degenne, A., Forsé M. (2003). Les Reseaux Sociaux. París: A. Colin.

Degenne, A., Lebeaux, M. O. (2005). "The dynamics of personal networks at the time of entry into adult life". Social Networks, 27: 337-358. 
Durkheim, E. (1990 [1912]). Les formes élémentaires de la vie religieuse. París: PUF.

Elchardus, M., Glorieux J. (1988). "Signification du temps et temps de la signification". En Mercure D, Wallemacq A. (Ed) : Les temps sociaux. Paris: De Boeck pgs. 97-118.

Elias. N. (1985). Time: An Essay. Oxford: Blackwell.

Erikson, B.H. (1982). "Networks, ideologies and belief systems". En Marsden, P., Lin, N. (Eds.): Social Structure and Network Analysis. Londres: Sage.

Farrugia, F. (1999). "Une brève histoire des temps sociaux: Durkeim, Halbwachs, Gurvitch". Cahiers internationaux de Sociologie, 106 :95-117.

Flick, U. (1998 [1995]). An Introduction to Qualitative Research. Londres: Sage.

Franzosi, R. (1994). "From words to numbers: A set theory framework for the collection, organization, and analysis of narrative data". En Marsden, P.V. (Ed): Sociological Methodology. Oxford: Blackwell.

Gartrell, C. D. (1987). "Network approaches to social evaluation". Annual Review of Sociology, 13: 49-66.

Ghiglione, R. (1982). "Analyse propositionelle el modèles argumentatifis". Connexions, 38: 89-106.

Ghiglione, R. ; Blanchet, A. (1991). Analyse de contenu et contenue d'analyse. París: Dunod.

Goffman, E. (1974). Frame Analysis: An essay on the organization of experience. New York: McGraw-Hill.

Gumperz, J. J. (1982a). Discourse Strategies. Cambridge: Cambridge University Press.

Gumperz, J. J. (1982b). Language and Social Identity. Cambridge: Cambridge University Press.

Gurvitch, G. (1962). Traité de sociologie (Volumen I y II). París: PUF.

Gurvitch, G. (1969). La vocation actuelle de la sociologie. (Volumen I y II). París: PUF 
Halbwachs, M. (1994 [1925]). Les cadres sociaux de la mémoire. París: Albin Michel.

Hymes, D. (1972). "Models of the Interaction of Language and Social Life". En Gumperz J. J., Hymes D. (Eds): Directions in Sociolinguistics: The Ethnography of Communication. New York: Holt, Rinehart and Winston.

Jovchelovitch, S., Bauer, M. W. (2000). "Narrative Interviewing". En Martin W. Bauer y George Gaskell (Eds.): Qualitative Researching with Text, Image and Sound. Londres: Sage.

Labov, W. S., Waletsky J. (1967). “Narrative Analysis: Oral Versions of Personal Experience". En Helm J. (Ed): Essays on the verbal and visual arts. Seattle: University of Washington Press.

Lejeune, P. (1989). “Memoria, diálogo y escritura”. Historia y fuente oral, 1: 33-67. López, P., Lozares C. (2007). “La conciliación entre las exigencias del ámbito productivo y las condiciones sociofamiliares: estudio de caso de una empresa". Papers, 83: 123-144.

Lozares, C. (2006). “Las representaciones fácticas y cognitivas del relato de entrevistas biográficas: un análisis del discurso". REDES. Revista hispana para el análisis de redes sociales, 10 \#8. Revista en línea <http://revistaredes.rediris.es>.

Lozares, C., López, P., Domínguez, M. (1998). “La articulación de ámbitos sociales a partir de la base temporal". Papers. 55: 115-130.

Lozares, C., López, P., Martí, J. (2004). “La relación entre los tiempos y las actividades del trabajo productivo y las actividades del trabajo productivo y reproductivo". Trabajo, 13: 165-186.

Lozares, C., Verd J. M. (2004). "Modelos de flexibililidad del trabajo y tiempo productivo". Trabajo, 13: 97-113.

Lozares, C., Verd, J. M., Martí, J., López, P. (2003). “Relaciones, redes y discurso: revisión y propuestas en torno al análisis reticular de datos textuales". Revista Española de Investigaciones Sociológicas, 101: 175-200. 
Mead, G. H. (1932). The Philosophy of the Present. Chicago: University of Chicago Press.

Mead, G. H. (1934). Mind, Self, and Society. Chicago: University Of Chicago Press

Miguélez, F., Torns, T. (Eds.) (2000). Temps i Ciutat. Barcelona: Consell Econòmic i Social de Barcelona.

Minor, M. J. (1983). "Panel data on ego networks: a longitudinal study of former heroin addicts". En R. S. Burt y M. J. Minor (Eds.) Applied Network Analysis. Sage: Beverly Hills.

Runyan, W. M. (1984). Life Histories and Psychobiography. Explorations in Theory and Method. New York/Oxford: Oxford University Press.

Schiffrin, D. (1994). Approaches to discourse. Oxford, UK: Blackwell.

Searle, J.R. (1969). Speech acts: An essay in the philosophy of language. Cambridge: Cambridge University Press.

Sorokin, P. A., Merton R. K. (1937). “Social Time; A Methodological and Functional Aanalysis". The American J ournal of Sociology, 42: 615-629.

Suitor, J. J, Wellman, B., Morgan, D. L. (Eds.) (1997). Change in Networks. Social Networks. 19 (edición especial).

Torns, T. (1994). Women and the distribution of time. En VV.AA.: A wider vision, Bruselas: IRIS-EC.

Verd, J. M. (2005). "El uso de la teoría de redes sociales en la representación y análisis de textos. De las redes semánticas al análisis de redes textuales". Empiria. Revista de metodología de ciencias sociales, 10: 129-150.

Verd, J. M. (2006). “La construcción de indicadores biográficos mediante el análisis reticular del discurso. Una aproximación al análisis narrativo-biográfico". REDES. Revista hispana para el análisis de redes sociales, 10 \#4. Revista en línea <http://revista-redes. rediris.es>.

Verd, J. M. (2007). "Análisis de narraciones sociobiográficas: una visión reticular, cognitiva y social". En Carlos Lozares (Ed). Interacción, redes sociales y ciencias cognitivas. Granada: Comares. 
Wallemacq, A. (1988). "Les tiemps sociaux, un pléonasme? Exercise de estyle". En Mercure D, Wallemacq, A. (Eds.) Les temps sociaux. Paris: De Boeck

Wellman, B. (1979). "The community question: the intimate networks of East Yorkers". American Journal of Sociology, 83: 1201-1231.

Wengraf, T. (2001). Qualitative Research Interviewing. Biographic Narrative and Semi-Structured Methods. Londres: Sage.

Wheeler, M. A. (2000). "Episodic Memory and Autonoetic Awareness". En Endel Tulving y Fergus I. M. Craik (Eds.): The Oxford Handbook of Memory. Oxford/New York: Oxford University Press.

Whitehead, A. N. (1969) Process and Reality. New York: Free Press. 